\title{
A New Species of Choricotyle (Monogenoidea: Diclidophoridae) from Ctenosciaena gracilicirrhus (Teleostei: Sciaenidae), a Marine Fish Occurring in the Littoral Zone from the State of Rio de Janeiro, Brazil
}

\author{
Author(s): Simone C. Cohen, Melissa Q. Cardenas, Berenice M. M. Fernandes, \\ and Anna Kohn
}

Source: Comparative Parasitology, 78(2):261-264.

Published By: The Helminthological Society of Washington

DOI: http://dx.doi.org/10.1654/4506.1

URL: http://www.bioone.org/doi/full/10.1654/4506.1

BioOne (www.bioone.org) is a nonprofit, online aggregation of core research in the biological, ecological, and environmental sciences. BioOne provides a sustainable online platform for over 170 journals and books published by nonprofit societies, associations, museums, institutions, and presses.

Your use of this PDF, the BioOne Web site, and all posted and associated content indicates your acceptance of BioOne's Terms of Use, available at www.bioone.org/page/ terms of use.

Usage of BioOne content is strictly limited to personal, educational, and non-commercial use. Commercial inquiries or rights and permissions requests should be directed to the individual publisher as copyright holder. 


\title{
A New Species of Choricotyle (Monogenoidea: Diclidophoridae) from Ctenosciaena gracilicirrhus (Teleostei: Sciaenidae), a Marine Fish Occurring in the Littoral Zone from the State of Rio de Janeiro, Brazil
}

\author{
Simone C. Cohen, ${ }^{1}$ Melissa Q. Cardenas, Berenice M. M. Fernandes, and Anna Kohn ${ }^{2}$ \\ Laboratório de Helmintos Parasitos de Peixes, Instituto Oswaldo Cruz, FIOCRUZ, Av. Brasil, 4365, Manguinhos, Rio de \\ Janeiro, RJ, Brazil, 21045-900
}

ABSTRACT: A new species of Choricotyle parasitizing the marine fish Ctenosciaena gracilicirrhus (Teleostei: Sciaenidae) from Angra dos Reis, Rio de Janeiro, Brazil $\left(23^{\circ} 00^{\prime} 24^{\prime \prime} \mathrm{S} ; 44^{\circ} 19^{\prime} 05^{\prime \prime} \mathrm{W}\right)$ is proposed. Choricotyle rohdei $\mathrm{n}$.sp. differs from all other species of the genus mainly by the number of genital spines, which varies from 28 to 30 , whereas others present 7 to 12 spines.

KEY WORDS: Choricotyle rohdei, Diclidophoridae, Monogenoidea, fish parasites, Ctenosciaena gracilicirrhus, Sciaenidae, Brazil.

Fishes of Sciaenidae range in shallow waters, usually over sandy mud bottoms and are among the most economically valued fish groups in coastal and estuarine waters. The family is represented in Brazil by 54 marine species (Souza et al., 2008). Ctenosciaena gracilicirrhus (Metzelaar) has been reported in the western Atlantic Ocean, ranging from coastal waters of Nicaragua to the Caribbean Sea and Atlantic coasts of South America to southern Brazil. It feeds mainly on shrimps and is an important food fish (Froese and Pauly, 2010).

Before the current study, 2 helminths had been reported from $C$. gracilicirrhus: the trypanorhynch cestodes Heteronybelinia annakohnae Pereira and Boeger, 2005 and Progillotia dollfusi Carvajal and Rego, 1983 (Pereira and Boeger, 2005). During a survey on fish parasites from Angra dos Reis, State of Rio de Janeiro, Brazil, a new species of Monogenoidea belonging to Choricotyle van Beneden and Hesse, 1863 was found parasitizing C. gracilicirrhus and is described herein.

\section{MATERIALS AND METHODS}

From August 2007 to February 2009, 203 specimens of C. gracilicirrhus were examined. Fish were obtained from Angra dos Reis, State of Rio de Janeiro, Brazil.

The gill arches were separated and the monogenoideans collected were fixed in $5 \%$ formaldehyde, with or without light cover-glass pressure. Specimens were stained with Langeron's alcoholic acid carmine, deydrated in an ethanol series, cleared in beechwood creosote, and permanently mounted in Canada balsam. The specimens were observed

\footnotetext{
${ }^{1}$ Corresponding author (email: scohen@ioc.fiocruz.br)

${ }^{2}$ Research fellow, Conselho Nacional de Desenvolvimento Científico e Tecnológico
}

with a Zeiss Axioskop 2 Plus microscope, figures were drawn with the aid of a drawing tube, and digital images were captured with a SONY MPEGMovie EX DSC-S75 digital camera.

Measurements are presented in micrometers as range values followed by the mean value, standard deviation, and number of measurements in parentheses. Prevalence, mean intensity, and range of infection were calculated according to Bush et al. (1997). Specimens studied were deposited in the Helminthological Collection of the "Instituto Oswaldo Cruz" (CHIOC) in Brazil. Terminology of clamp sclerites follows Euzet and Suriano (1975).

\section{Choricotyle rohdei n.sp.}

(Figs. 1-6)

\section{Description (on the basis of $\mathbf{3 2}$ stained and mounted specimens)}

Body elongated, set off from haptor, 1,040-3,700 $(2,120 \pm 797.6 ; n=21)$ long $\times 170-860(534 \pm$ $186.9 ; n=24)$ maximum width and 160-760 (478 $\pm 159.1 ; n=23)$ wide at ovarian level. Two anterior suckers, $50-80(66 \pm 8.6 ; n=34)$ long $\times 52-92(76$ $\pm 8.7 ; n=34)$ wide, posterior to oral aperture. Mouth subterminal, ventral. Pharynx ovoid, 87-137 $(112 \pm 16.4 ; n=14)$ long by $65-105(85 \pm 11.9 ; n$ $=14$ ) wide, lying behind the suckers. Esophagus present, bifurcating at level of genital atrium. Intestinal ceca confluent, uniting posteriorly, penetrating haptor, but not entering on peduncles.

Haptor 300-760 (485 $\pm 157.8 ; n=13)$ long, with 8 long peduncles, $360-610(471 \pm 68.3 ; n=23)$ long, each with one clamp. Clamps similar in size, measuring 100-175 (146 $\pm 17.5 ; n=95)$ long by 110-230 (158 $\pm 21 ; n=95)$ wide, with an accessory sucker and an oval, small accessory sclerite in axial quadrant of the clamp, measuring 30-65 (49 $\pm 10.6 ; n$ 


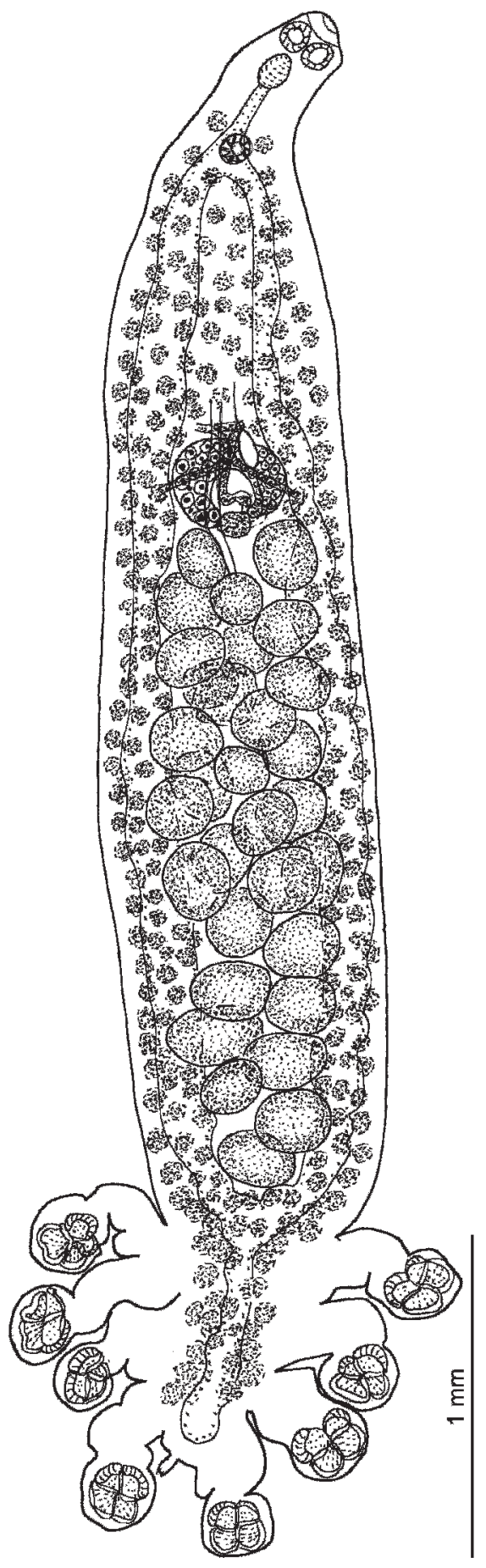

Figure 1. Choricotyle rohdei n.sp., whole mount, ventral view, holotype.
$=30$ ) long. Ma, the anterior portion of anterior jaw medial sclerite, is curved ventrally, reaching curvature of As, the axial sclerite of anterior jaw. Pl1 and Pl2 are sclerites bordering lateral portion of posterior jaw and Ps1 and Ps2 are sclerites bordering axial portion of the posterior jaw. Pl1 and Ps1 are curved, with anterior extremity thin. Pl2 and Ps2 sclerites present recurved points and grooves reaching $\mathrm{O}$ sclerite, the median sclerite of posterior jaw. O sclerite presents posterior extremity bifurcated, reaching Pl2 and Ps2. Terminal lappet 70-110 (88 $\pm 14.5 ; n=6)$ long at posterior extremity, between fourth and fifth clamp pairs, presenting 2 pairs of hooks.

Genital atrium spherical, midventral 50-70 (60 \pm $5.8 ; n=18)$ long $\times 45-77(63.6 \pm 9.04 ; n=18)$ wide, with 28 to 30 spines disposed in a single concentric row around genital atrium. Spines 16-23 $(19.6 \pm 1.88 ; n=78)$ long, pointed toward the opening.

Testes 95-280 $(165 \pm 47.8 ; n=48) \times \mathrm{x} 100-235$ (161 $\pm 36.4 ; n=48)$, intercecal, postovarian, varying from 21 to $36(26 \pm 4.73 ; n=15)$ in number, mostly posterior to midbody.

Ovary inverted U shaped; oviduct receives duct from oval seminal receptacle. Ootype and Mehlis' gland located in posterior margin of ovary. Transverse vitelline ducts join at anterior margin of ovary forming vitelline reservoir that reaches the oviduct. Vitelline follicles coextensive with intestinal ceca, occupying most part of body and extending into haptor. Uterus running anteriorly to genital atrium. Vagina absent. One egg with 2 polar filaments was observed in 1 specimen, measuring $125 \times 65$ without the filaments.

\section{Taxonomic summary}

Type host: Ctenosciaena gracilicirrhus (Metzelaar) (Sciaenidae), common named "cangauá".

Type locality: Angra dos Reis, State of Rio de Janeiro, $23^{\circ} 00^{\prime} 24^{\prime \prime} \mathrm{S} ; 44^{\circ} 19^{\prime} 05^{\prime \prime} \mathrm{W}$.

Site of infection: Gill lamellae.

Prevalence: $26.1 \%$ (53 infected of 203 examined).

Mean intensity of infection: $1-19(1.92 \pm 2.54)$.

Specimens deposited: Holotype CHIOC no. 37473a; 31 paratypes CHIOC no. 37473b; 37474a, b; 37475; 37476a, b; 37477a, b; 37478; 37479a, b; 37480; 37481; 37482; 37483a, b, c; 37484a, b; 37485; 37486; 37487; 37488a, b; 37489a, b, c; 37490a, b, c; 37491.

Etymology: The specific name is given for Professor Klaus Rohde in recognition of his scientific contribution to the knowledge of monogenoids. 

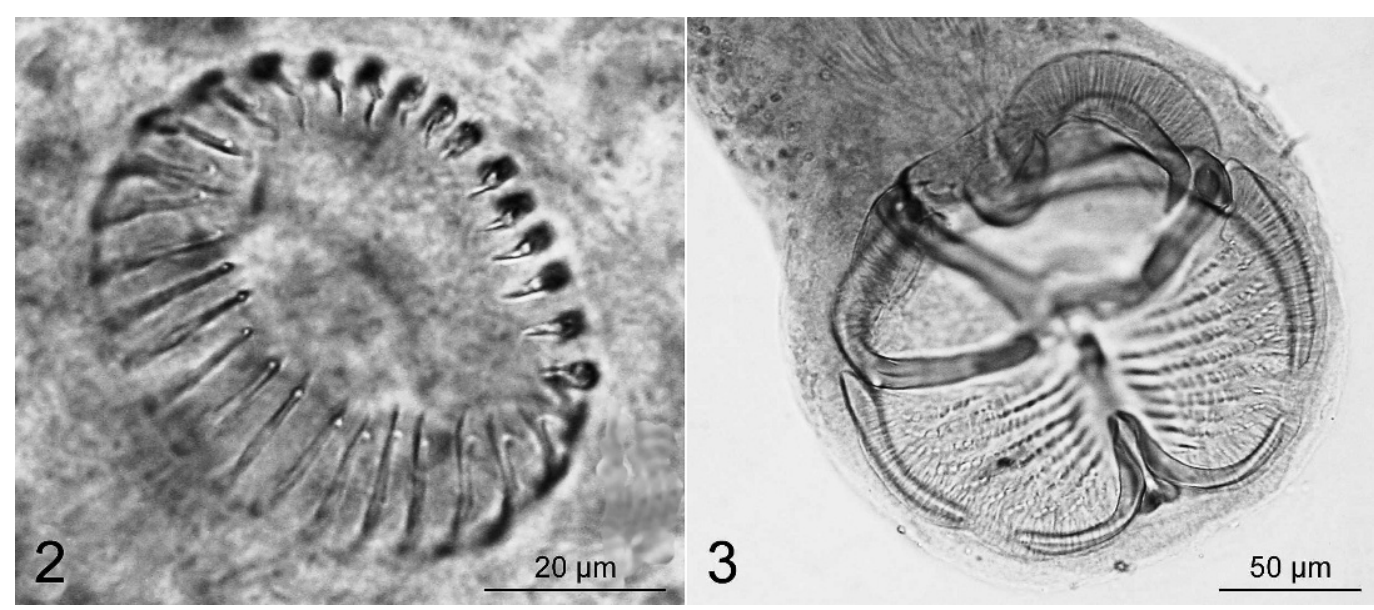

Figures 2, 3. Choricotyle rohdei n.sp. 2. Genital atrium presenting 30 spines. 3. Detail of a clamp.

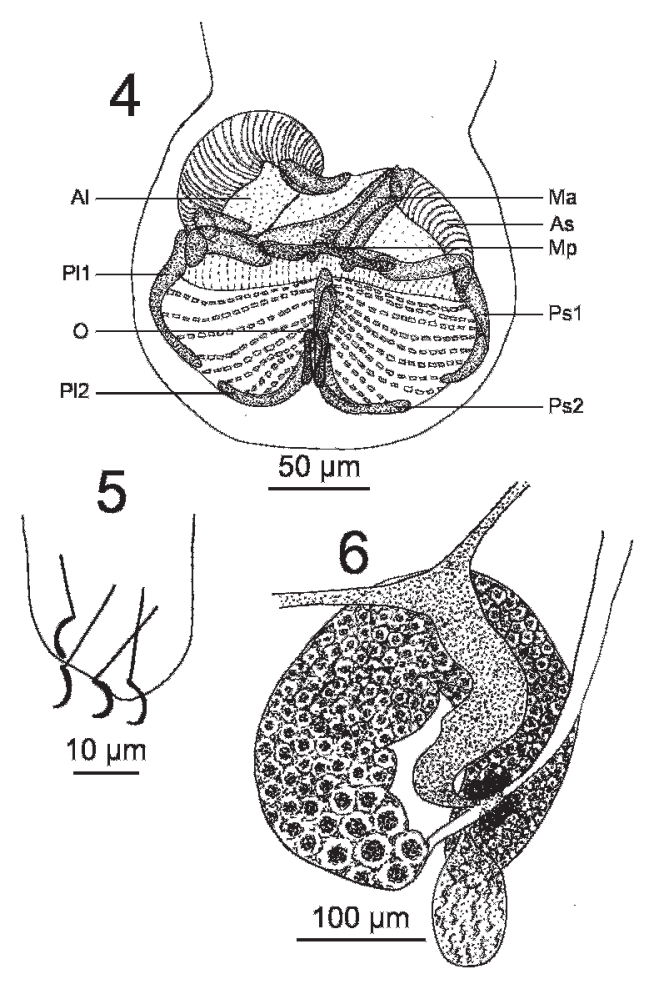

Figures 4-6. Choricotyle rohdei n.sp. 4. Clamp. 5. Terminal lappet with two pairs of hooks. 6. Detail of female reproductive system. (Ma, anterior portion of anterior jaw medial sclerite; As, axial sclerite of anterior jaw; Pl, sclerites bordering lateral portion of posterior jaw; Ps, sclerites bordering axial portion of the posterior jaw; O, median sclerite of posterior jaw.)

\section{Remarks}

The new species has been assigned to Choricotyle as defined by Yamaguti (1963) on the basis of the presence of 4 pairs of pedunculated clamps provided with a typical sucker in expanded inner dorsal quadrant, genital atrium with spines arranged in a single row, coextensive vitellaria and intestinal ceca, and absence of vagina.

Mamaev (1976) listed 20 species in Choricotyle and considered 5 of these as species inquirenda. Oliva (1987) considered only 10 species belonging to Choricotyle, considering that some species were transferred to other diclidophoridean genera. Luque et al. (1993) described 2 new species of Choricotyle and revalidated another one, considering a total of 19 valid species. Lamothe-Argumedo et al. (1998) described one more species from Mexico and considered Choricotyle exilis Crane, 1972 as a valid species, bringing the total number of species in the genus to 21. Recently, Oliva et al. (2009) erected 2 new species in the genus, and considered there to be only 15 valid species in the genus. However, they did not specify which species they considered invalid.

To date, the species considered valid by the above authors combined are: Choricotyle anisotremi Oliva, 1987, Choricotyle aspinachorda Hargis, 1955, Choricotyle australiensis Roubal, Armitage and Rohde, 1983, Choricotyle brasiliensis Luque, Amato and Takemoto, 1993, Choricotyle caudalis (Koratha, 1955), Choricotyle caulolatili (Meserve, 1938), Choricotyle chrysophryi van Beneden and Hesse, 1863 (type species), Choricotyle crassicaudata Mamaev and Aleshkina, 1984, Choricotyle cynoscioni (Mac Callum, 1917), Choricotyle elongata 
(Goto, 1894), C. exilis Crane, 1972, Choricotyle hysteroncha (Fujii, 1944), Choricotyle isaciensis Oliva, González, Ruz and Luque, 2009, Choricotyle labracis (Cerfontaine, 1895), Choricotyle leonilavazquezae Lamothe-Argumedo, Aranda-Cruz, and Perez-Ponce de Leon, 1998, Choricotyle multitesticulae (Chauhan, 1945), Choricotyle oregonensis McCauley and Smoker, 1969, Choricotyle orthopristis Luque, Amato, and Takemoto, 1993, Choricotyle pellonae Kritsky and Bilqees, 1973, Choricotyle polynemi Mamaev, 1972, Choricotyle scapularis Oliva, González, Ruz, and Luque, 2009, Choricotyle simplex Mamaev, 1976, and Choricotyle sonorensis Caballero and Bravo-Hollis, 1962.

The main feature that differentiates the new species from others of the genus is the number of genital spines, which varies from 28 to 30 in Choricotyle rohdei $\mathrm{n}$.sp., whereas all other nominal species have 7 to 12 spines.

The oval accessory sclerite has been observed in $C$. aspinachorda by Hargis (1955), C. anisotremi by Oliva (1987), and C. isaciensis by Oliva et al. (2009). According to Oliva (1987), this oval sclerite was also described in Choricotyle louisianensis by Hargis (1955), and by Tantalean (1974) in Choricotyle peruensis and Choricotyle chimbotensis, but these species are now considered to belong to Hargicotyle Mamaev, 1972.

\section{ACKNOWLEDGMENTS}

We are grateful to Antonia Lucia dos Santos for help in the collection of fish and to the Laboratorio de Monitoração Ambiental, from Eletronuclear, Angra dos Reis, State of Rio de Janeiro for the facilities offered to examine the fishes, to Heloisa Nogueira Diniz, from Laboratório de Produção de Imagens, Instituto Oswaldo Cruz for the aid with the plates, and to anonymous referees for the suggestions to improve the paper.

\section{LITERATURE CITED}

Bush, A. O., K. D. Lafferty, J. M. Lotz, and A. W. Shostak. 1997. Parasitology meets ecology on its own terms: Margolis et al. revisited. Journal of Parasitology 83(4):575-583.
Euzet, L., and D. M. Suriano. 1975. Orbocotyle marplatensis n.g., n.sp. (Diclidophoridae) Monogène parasite branchial de Téléostéens marins du genre Prionotus (Triglidae) en Argentine. Bulletin du Museum D'Histoire Naturelle, Paris, 3a Ser., Zoologie 192: 11-22.

Froese, R., and D. Pauly. 2010. FishBase. World Wide Web electronic publication. Available from: www. fishbase.org version 03/2010

Hargis, W. 1955. Monogenetic trematodes of Gulf of Mexico fishes. Part IX. The family Diclidophoridae Furhmann, 1928. Transactions of the American Microscopical Society 74:337-388.

Lamothe-Argumedo, R., C. Aranda-Cruz, and G. Pérez Ponce de Leon. 1998. Choricotyle leonilavazquezae sp.n. (Monogenea: Diclidophoridae) parasitic on $\mathrm{Mi}$ crolepidotus brevipinnis (Ostheichthyes: Haemulidae) from Chamela Bay, Jalisco, Mexico. Journal of the Helminthological Society of Washington 65:24-30.

Luque, J. L., J. F. R. Amato, and R. M. Takemoto. 1993. Four species of Choricotyle Van Beneden and Hesse (Monogenea: Diclidophoridae: Choricotylinae) parasitic on Orthopristis ruber (Cuvier) (Ostheichthyes: Haemulidae) from the Brazilian coast, with description of two new species. Revista Brasileira de Parasitologia Veterinaria 2:15-24.

Mamaev, Y. L. 1976. The system and phylogeny of monogeneans of the family Diclidophoridae. Trudy Biologo-Pochvennogo Instituta, U.S.S.R., Vladivostok 35:57-80.

Oliva, M. E. 1987. Choricotyle anisotremi n.sp. (Monogenea: Diclidophoridae) parasitic on Anisotremus scapularis (Tschudi) from the northern Chilean coast. Systematic Parasitology 10:129-133.

Oliva, M. E., M. T. González, P. M. Ruz, and J. L. Luque. 2009. Two new species of Choricotyle Van Beneden and Hesse (Monogenea: Diclidophoridae), parasites from Anisotremus scapularis and Isacia conceptionis (Haemulidae) from northern Chilean coast. Jounal of Parasitology 95:1108-1111.

Pereira, J., and W. A. Boeger. 2005. Larval tapeworms (Platyhelminthes, Cestoda) from sciaenid fishes of the southern coast of Brazil. Zoosystema 27:5-25.

Souza, U. P., R. C. Costa, I. A. Martins, and A. Fansozo. 2008. Relationships among Sciaenidae fish (Teleostei: Perciformes) and Penaeoidea shrimp (Decapoda: Dendrobranchiata) biomass from the north coast of São Paulo State, Brazil. Biota Neotropica 8:83-92.

Tantalean, M. V. 1974. Monogeneos de la familia Microcotylidae Taschenberg parasitos de peces del mar peruano con descripcion de una especie nueva. Biota 10:120-127.

Yamaguti, S. 1963. Systema Helminthum. Volumn IV. Monogenea and Aspidocotylea. Interscience Publishers, New York. 699 pp. 